\title{
THE CLASSIFICATION AND CHEMICAL PATHOGENESIS OF URINARY CALCULI
}

\author{
By JOHN F. McINTOSH \\ (From the McGill University Clinic and Department of Medicine, Royal Victoria \\ Hospital, Montreal)
}

(Received for publication May 25, 1942)

Classifications of urinary calculi are of two sorts, simple and complex. Wollaston's (1) scheme (1810), will serve as an example of the former. He named 6 classes of stones: (1) uric acid; (2) oxalate of lime; (3) phosphate of lime; (4) ammoniacal phosphate of magnesia; (5) fusible calculus (a mixture of the last two); and (6) cystic oxide (cystine). One may observe that Wollaston named only one mixture in his scheme, and so solved the question of classifying mixed stones by neglecting it. Heller's (2) classification (1860), which has been reproduced in countless textbooks and profoundly influenced the literature of the subject, is also one of the simple sort. It mentions 8 classes, some of them very rare or unimportant. The classifications used by numerous surgical authors who have treated the question of calculi in text-books or journal articles are often of the simple type.

The tendency among analysts has been towards complex classifications. These are likely to list not only the simple chemical constituents but also the various mixtures which have been observed. A recent classification of this type is that of Domanski (3), which makes use of 13 headings.

It has become customary to speak of the stones as composed of carbonates, phosphates, or oxalates, so that attention is focussed upon the acid radicals, rather than upon the salts as a whole or upon the metallic content. This tendency has had two unfavourable consequences. Attention has been directed away from the metallic elements, which happen to have far more physiological significance; and in the case of phosphates, as we shall see, these stones have often been lumped in a single group, which, on the grounds of pathogenesis, should certainly be subdivided. Hence, while many tables of composition in the literature contain irrelevant detail, others omit facts of etiologic significance.

The present paper presents a classification based upon the chemical pathogenesis underlying stone formation and evidence supporting the clinical value of chemical analysis of urinary calculi. For the purposes of this article, it is unnecessary to consider anatomical defects, developmental or acquired, or pathologic processes, such as the papillary plaques described by Randall (4), although these may often have an important place in the pathogenesis of stones. It is generally recognized that an organic "matrix" can be demonstrated in most stones, but whether this "matrix" is "primary" or "secondary" is beside the point. The chemical mechanisms which concern us do not necessarily have to do with the earliest origin of a concretion, but rather with this question: Granted that a calculus has had its origin, what are the conditions which allow urinary solutes to continue to be deposited upon its surface? A widely accepted view is the assumption that there is a "protective colloid mechanism," which ordinarily prevents precipitation of sparingly soluble substances from the urine. Derangement of this mechanism is supposed to permit the deposition of such substances as are present in excess of their solubility. Without examining this hypothesis in detail, it is fair to say that there is little direct evidence in its favour, and that the weight of experimental proof is against it $(5,6)$. The results of the present study lend it no support, for we do not find mixed stones containing all possible stoneforming constituents, nor miscellaneous mixtures, such as the "protective colloid" theory would lead one to expect. We find, as a matter of fact, a limited number of combinations, not more than four or five, each of which would appear to depend upon a chemical mechanism of its own.

The solubility in urine of any stone-forming substance is not a simple matter, since this solubility may deviate widely from its solubility in pure water, depending upon the composition of the urine. It has been shown that urinary salts 
have a marked effect upon the solubility of one another (7), and that complex formations sometimes occur, leading to very considerable increases in solubility. Quantitative studies of these effects have been made by Hammarsten ( 8 ) and Medes (9). There is no reason to doubt that factors of this sort influence the amount of stone-forming substances which the urine is able to hold in solution, and that they may frequently determine whether a calculus will form and grow, or tend to regress. Hammarsten has demonstrated the importance of solubility effects in determining the genesis of experimental calculi in the rat (6), and in influencing their regression (10), with special reference to the importance of magnesium in the case of calcium oxalate stones. In dealing with the general question of solubilities, the importance of urinary $\mathrm{pH}$ is well known.

Having briefly mentioned the principles which limit solubility in normal urine, we may now consider those factors which determine whether these limits will be exceeded or not. Aside from the matter of urine volume, these are two in number, diet and intermediary metabolism. It will be worth while to examine each of these in relation to each type of stone.

Uric acid stones. These stones usually consist of the free acid and are formed in acid urine. It is generally agreed that a strongly acid urine is the most important factor in their genesis-a belief supported by clinical experience (11) and experimental work (12). The likelihood of such stones may be increased as a result of excessive purine in the diet, as shown by Hammarsten's (12) experiments, or the uric acid may be of endogenous origin, as in cases of gout (11) and of leukemia (13).

The mechanism underlying the formation of ammonium urate stones is not at all clear. Hammarsten (14) is of the opinion that they may be formed independently of infection.

Cystine stones. These are only to be found in cases of cystinuria, and are the best example of a type of stone due to a derangement of intermediary metabolism. In a well-marked case, the urine may contain 0.4 to 1.0 grams of cystine per day. Although part of this cystine is considered to be endogenous in origin, there is reason to believe that it is mainly exogenous and derived from dietary methionine (15). If the urine is rendered strongly alkaline, the cystine may sometimes be kept in solution (16).

Xanthine stones. These stones are so rare in the human that little or nothing is known of the mechanisms underlying their formation. There is doubtless some derangement of purine metabolism, leading to excessive excretion of this substance in the urine.

Primary calcium stones. This term may be used to designate the large group of stones composed of calcium salts which are not the direct result of urinary tract infection. This group is an important one, making up more than half the total number of cases in many communities. The stones are composed of the calcium salts of oxalic, phosphoric, carbonic, and perhaps citric and other organic acids. A review of the literature leaves one with the impression that the grouping is a valid one, since the element calcium appears to play the chief rôle, to which the rôle of the acid radicals is subsidiary. There seems to be some reason to think that excessive urinary excretion of calcium is an important factor in the group as a whole. Such excess may have an extrinsic cause, such as diet or medication, and strong evidence has been adduced in favour of the hypothesis. On the other hand, the hyperexcretion may arise from internal disease or metabolic error, such as hyperparathyroidism. Although it is suspected that such an excess is common, we do not know how often primary calcium calculi are accompanied by excessive urinary excretion of calcium in clinical cases.

The literature of experimental calcium lithiasis is too complex and extensive to permit a summary to be brief and at the same time adequate. Avitaminosis, especially a partial avitaminosis A has led to a high incidence of stone in the hands of most investigators (17 to 19). Hypervitaminosis D has also been successful, alone (20), and in combination with avitaminosis A (21). There seems to be good evidence that excessive calcium in the diet may be a factor in stone production $(22,23)$, although some investigators (24) prefer to regard an imbalance of the $\mathrm{Ca}: \mathrm{P}$ ratio as the cause (24). Paradoxically, insufficient calcium in the diet may lead to greatly increased excretion of calcium in the urine; low magnesium intake also tends to cause a negative calcium balance, and if both elements are deficient in the 
diet, Hammarsten has observed summation of these effects $(6,10)$. These experiments are of the greatest interest, for she found that if the diet yielded a low urine $\mathrm{pH}$, calcium oxalate stones were formed. With an increase in $\mathrm{pH}$, she found an increase in calcium phosphate calculi, and she pointed out that others had found phosphate, carbonate, and possibly citrate stones, when urine $\mathrm{pH}$ deviated towards the alkaline side. From these experiments, it would appear that hypercalciuria, however produced, is the determining factor in the production of calcium stones, while the acid radical with which it is combined is largely dependent upon the $\mathrm{pH}$ of the urine.

The relationship between hyperparathyroidism and calculi has been well studied (25 to 27). The decalcification of bone, the hypercalcemia, and the excessive excretion of calcium in the urine are well established. Excessive excretion of phosphate also occurs (28). As pointed out by Albright, Aub and Bauer (29), these factors favor the formation of calcium phosphate stones. But Hunter and Turnbull (25) found carbonate present, while Barney and Jones (30) and Albright, Sulkowitch and Chute (31) have reported calcium oxalate stones. While these authors have not correlated the type of stone with the $\mathrm{pH}$ of the urine in these cases, the analogy to Hammarsten's experimental work is unmistakable.

Excessive urinary excretion of calcium may also occur following disease and injury of bone, and as a result of rarefaction incidental to bed rest and fixation of the limbs (32). Cases of this sort sometimes suffer from stones in the kidney pelvis. As the stones are radio-opaque and may arise independently of infection, they are presumably primary calcium stones. When these patients became ambulatory, the stones frequently disappear. This sequel is probably accompanied by a striking decrease in urinary calcium and by recalcification of the skeleton. Other causes of excessive excretion of calcium in the urine include hypervitaminosis $D$, hyperthyroidism, and acidosis. These factors are less definitely linked to urinary lithiasis. Cushing's syndrome should also be mentioned.

Flocks (33) has recently called attention to excessive calcium excretion in the urine of patients suffering from calcium urolithiasis. He attributed two of his cases to hyperparathyroidism, others to intrinsic renal changes. No explanation could be found for the remainder. It seems unlikely that the excessive urinary calcium could be due to a dietetic cause, since control cases on the same diets failed to show excessive excretion. Organisms were found in the urines of all patients, some of them urea-splitting types. Hence some of the calculi may not have been primary calcium stones. His results have not been confirmed. But, even if they prove to be misleading, it is certain that numerous human cases are to be observed in which primary calcium stones are associated with excessive urinary excretion of calcium. Can such stones arise when calcium excretion is normal? Although specific proof by quantitative urine studies is lacking, general clinical experience would suggest that they can. If so, the factors which influence the solubility of sparingly soluble calcium salts in urine assume great importance ( 7 to 9 ).

Magnesian stones. The importance of ureasplitting bacteria in the genesis of calculi was discovered as early as 1925 (34), and is now widely recognized. The literature seems to agree that $P$. ammoniae and $P$. Morgani are always ureolytic, and that organisms of the MicrococcusStaphylococcus group are frequently so. Pseudomonas aeruginosa ( $B$. pyocyaneus) and $H$. influenzae would appear to have clinical significance, while members of the coliform and diphtheroid groups are in a doubtful position. Chute and Suby (35) find that urea-splitting organisms account for 54 per cent of all cases in the Stone Clinic of the Massachusetts General Hospital. In these cases, the hydrolysis of urea is the first of a series of chemical reactions of which the following are the most important:

$$
\begin{array}{ll}
\mathrm{NH}_{2} \cdot \mathrm{CO} \cdot \mathrm{NH}_{2}+2 \mathrm{H}_{2} \mathrm{O} & \rightarrow 2 \mathrm{NH}_{4}++\mathrm{CO}_{3}^{--} \\
\mathrm{Mg}^{++}+\mathrm{NH}_{4}^{+}+\mathrm{PO}_{4}^{---} & \rightarrow \mathrm{NH}_{4} \mathrm{MgPO}_{4} \downarrow \\
\mathrm{Ca}^{++}+\mathrm{CO}_{3}^{--} & \rightarrow \mathrm{CaCO}_{3} \downarrow \\
3 \mathrm{Ca}^{++}+2 \mathrm{PO}_{4}^{---} & \rightarrow \mathrm{Ca}_{3}\left(\mathrm{PO}_{4}\right)_{2} \downarrow
\end{array}
$$

The essential point in these reactions is the alkalinity caused by the free ammonia. The chief characteristic of the stones is the presence of magnesium. When found, it should always raise the question of the presence of a urea-splitting organism. The quantitative composition of the stones, however, is dependent upon the composition of the urine in which they are formed. The amount of calcium and phosphate being excreted 
will obviously find reflection in the amounts of calcium carbonate and calcium phosphate found in the stone, and these may exceed the magnesium. Hellström (36) has pointed out that stones formed in association with $P$. ammoniae sometimes contain ammonium urate and calcium oxalate in addition to the salts already mentioned. We have been able to verify this observation.

The question as to whether all magnesian stones in the human are due to urea-splitting organisms or not requires further study. It is not impossible that phosphates of magnesium may be precipitated by a mechanism similar to that which may be observed in cases of phosphaturia. Such a phenomenon might take part in the formation of bladder stones. Another mechanism which might conceivably exist would be the substitution of magnesium for calcium in a calculus.

\section{CLASSIFICATION OF A SERIES OF URINARY CALCULI}

In Table $I$, is presented a summary of the analyses of 100 consecutive urinary calculi examined in the Medical Laboratories, McGill University Clinic, Royal Victoria Hospital. The scheme offers a new basis of classification, as it is based chiefly upon the presence or absence of the metallic elements. It has grown out of the routine use of the analytical scheme proposed in the preceding paper. Examination of the table will show that it can readily be correlated with present views of the mechanism of stone production as these have been outlined above.

\section{TABLE I}

\begin{tabular}{|c|c|c|c|c|c|}
\hline Type & Kidney & Ureter & Bladder & $\begin{array}{c}\text { Pros- } \\
\text { tate } \\
\text { urethra }\end{array}$ & Total \\
\hline $\begin{array}{l}\text { Uric acid . . . . . . . . } \\
\text { Ammonium urate . . } \\
\text { Cystine . . . . . . . . . } \\
\text { Calcium oxalate..... } \\
\text { Calcium phosphate- } \\
\text { carbonate . . . . . . . } \\
\text { Magnesian . . . . . . }\end{array}$ & $\begin{array}{r}4 \\
1 \\
19 \\
5 \\
13\end{array}$ & $\begin{array}{r}4 \\
28 \\
1 \\
5\end{array}$ & $\begin{array}{r}2 \\
1 \\
2 \\
2 \\
11\end{array}$ & $\begin{array}{l}1 \\
1\end{array}$ & $\begin{array}{r}10 \\
1 \\
1 \\
50 \\
\\
9 \\
29\end{array}$ \\
\hline Total.......... & 42 & 38 & 18 & 2 & 100 \\
\hline
\end{tabular}

In preparing the table, the stones have been arranged entirely on the basis of chemical analysis, without reference to apparent etiology or other clinical facts. It has seemed worth while to specify the anatomical site as well as the composition, as this fact has clinical significance and geo- graphical interest, quite apart from the primary objects of this paper. Cases with stones in multiple sites have not been indicated. Recurrent stones have not been counted more than once, except in one or two instances in which a change in composition has taken place. When a change of this sort has occurred during the formation of the stone, it has been classified according to the composition of the nucleus, and the nature of the envelope has been indicated in the text.

\section{COMMENT}

\section{Class $A$. Organic stones}

\section{Stones containing uric acid}

There were 11 stones in this group. All of them have been tested by Ehrlich's diazo test to determine whether xanthine was present. All were found negative. Ten of them were composed almost entirely of uric acid. The single ammonium urate stone calls for special comment.

Case 1: A diabetic of 70 years proved to be suffering from prostatic obstruction and a large bladder calculus. Upon removal, it measured $55 \mathrm{~mm}$. in diameter and weighed approximately 50 grams. The brown chalky nucleus, $30 \mathrm{~mm}$. in diameter, was composed of ammonium urate, calcium carbonate, and phosphate, but was entirely free of magnesium. Surrounding it was an envelope of white chalky appearance, containing carbonate, phosphate, calcium, ammonium, and magnesium. This envelope was apparently due to the action of a urea-splitting organism. On culture, Micrococcus, Aerobacter, and a coliform organism were isolated. The nucleus would appear to have been formed in alkaline urine before the advent of the urea-splitting invader. Since the ash of the nucleus after ignition amounted to 55 per cent, it might have been classified among the carbonate-phosphate group of primary calcium stones. It seems likely that at least two mechanisms were operative in forming this nucleus.

\section{Cystine stones}

Only one case exhibiting cystine stones has come under observation. The patient has suffered from numerous recurrences over many years. The stones are practically pure cystine.

\section{Class $B$. Primary calcium stones}

This class might perhaps be said to comprise those inorganic stones which are not secondary to infection. It is important to note that stones containing carbonate and phosphate may belong here or in the magnesian group, depending on the presence or absence of magnesium. To divide the 
inorganic stones in this way has etiologic significance; to call them carbonates and phosphates has none. It is worth noting that none of the stones of this class contain more than a trace of ammonia.

\section{Calcium oxalate stones}

This group, 50 in number, is by far the largest in our series, and equal to all the rest combined. It is naturally part of the class of primary calcium stones, and shows its relation to the carbonatephosphate group by the fact that calcium carbonate and calcium phosphate are often found as minor constituents. Occasionally, they may make up the major part of the stone, and calcium oxalate, the minor one. In this way, our clinical findings tend to confirm the experimental work of Hammarsten $(6,10)$ which establishes the primary calcium stones as a class.

On the other hand, the oxalate stones should not be allowed to lose their identity as a group, especially for therapeutic reasons. Among 53 primary calcium stones containing oxalate, it has proved to be the major constituent in 50. It is well recognized that these stones are associated with acid urine (37), and this fact has satisfactory experimental confirmation $(6,10)$. Forty-six of our cases have records of urinary acidity. In 45 of them, the urine has been acid to litmus. The single case with alkaline urine had only one examination.

It is generally agreed that these stones are not caused by urinary infection (38). The clinical histories and urine studies in our cases would tend to confirm this opinion. Although significant numbers of pus cells were noted in the urine in 11 instances, these were usually scanty or absent.

One stone is of considerable interest, as it illustrates the two groups which make up the class of primary calcium stones. Another was a complication in a case of hyperparathyroidism.

Case 2. A man, 35 years of age, had suffered from recurrent calculi for 10 years. A ureteral stone weighing 339 mgm. was removed through the cystoscope.' It resembled a snail shell in shape. The nucleus was composed of hard brown crystalline material, which proved to be calcium oxalate. Around it was a white chalky envelope whose major constituent was calcium phosphate; there was a minor amount of calcium carbonate and only a trace of oxalate. Magnesium was absent. It seems likely that the nucleus of this stone developed in acid urine. Perhaps due to a change in diet, the urine deviated towards alkalinity and the salts characteristic of alkaline urine were deposited. The urine specimens examined on admission were acid to litmus. On culture, a diphtheroid organism was found, but was probably without significance, since the urine sediment contained only occasional white cells.

Case 3. A female, aged 53 years, suffered from a stone in the kidney. $\mathrm{X}$-ray pictures showed an area of decalcification in the tibia which was regarded as evidence of hyperparathyroidism. The serum calcium was $12.1 \mathrm{mgm}$. per cent. The stone was removed by operation, and proved to be predominantly calcium oxalate, with a smaller amount of calcium phosphate. Exploration of the parathyroids was not carried out.

It is very interesting to observe that none of the calcium oxalate stones contained uric acid. Since both of these substances tend to precipitate in acid urine, one would expect them to occur together at times. Although such mixtures have been frequently observed in other laboratories, they seem to be very rare in the Montreal area. Fowler (39) has observed only one uric acidcalcium oxalate stone among a series of 250 examined at the Montreal General Hospital.

\section{Primary calcium phosphate-carbonate stones}

This group contains the primary calcium stones, 9 in number, in which calcium oxalate did not predominate. By analogy with animal experiments, one would expect them to have been formed in neutral or alkaline urine. In 7 of our cases in which the reaction of the urine has been recorded, it has usually been acid to litmus. These observations may, of course, reflect the hospital diets, and bear little relation to the reaction of the urine at the time the stones were being formed. Two cases of hyperparathyroidism are included in the group.

Case 4. An adult female was admitted to another institution on account of spontaneous fractures. She was bedridden and in poor physical condition. Subtotal thyroidectomy with removal of 2 parathyroids was carried out. One of the latter showed moderate enlargement. At autopsy, stones and gravel were found in the kidneys. The bones were decalcified to an extreme degree, and there was extensive metastatic calcification of the viscera. The stone specimens were composed of calcium carbonate and phosphate, without oxalate, magnesium, or uric acid.

Case 5. An adult male suffered from a series of recurrent stones over a period of 2 years. $\mathrm{He}$ was admitted to another hospital, where X-ray pictures of the bones showed extensive changes said to be compatible with a diagnosis of Paget's disease. The serum calcium showed values ranging from 11 to $18 \mathrm{mgm}$. per cent. Urine $\mathrm{pH}$ was recorded as 5.5 and 6.0. Stones were removed through the cystoscope, and at a later date by ureterotomy. They were found to consist chiefly of cal- 
cium phosphate with a smaller amount of calcium carbonate. Uric acid, magnesium, and oxalate were absent.

None of the other cases in the group have shown clinical evidence pointing to excessive excretion of calcium. Among 59 cases of primary calcium stones, blood calcium values have been normal in 21 , elevated in 2 , and low in 1. In 35 instances, including Case 4 , the determination has not been carried out.

\section{Group 5}

\section{Class C. Magnesian stones}

Twenty-nine stones in our series belong in this group. Although these stones, like group 4, contained considerable amounts of calcium carbonate and phosphate, they differed from them in containing magnesium and ammonium. The tests for these 2 substances showed a good parallelism with one another. They were present in large or moderate amounts in 27 instances, while in 2 cases they were found in small amounts. This finding is at variance with the statement, frequently made, that magnesium phosphate (presumably $\left.\mathrm{Mg}_{8}\left(\mathrm{PO}_{4}\right)_{2}\right)$ is one of the constituents of stones. This opinion seems to be traceable to Heller (2), who states that magnesium phosphate is to be found without ammonia, "or, at least only traces of ammonia." It seems likely that this statement has misled many subsequent writers $(40,41)$. I have not been able to find any quantitative data which would support such a contention.

As mentioned above, small amounts of calcium oxalate and ammonium urate have been found in some of these stones.

Cultures of the urine were made in 15 of the 29 cases. P. ammoniae was present 6 times, and was always associated with alkaline urine. Micrococcus was present 5 times, a urea-splitting Staphylococcus once; in 3 cases, other organisms were present. Among the 14 cases which were not cultured, there was presumptive evidence of infection in 12, while in 2 the evidence was insufficient to form an opinion. It is clear that there is a close correlation between urinary infection and the presence of magnesium as a constituent.

From this series of cases, it is impossible to say whether magnesian stones can arise in the human in the absence of urea-splitting organisms. If such cases occur at all, they are probably few in number. No magnesium carbonate stones have been observed although such have been reported in animals.

\section{SUM MARY}

1. A brief summary is given of present-day views of the chemical mechanisms underlying the formation of urinary calculi.

2. A method for classification of calculi is presented, based principally upon the presence or absence of metallic elements.

3. This method of classification has the advantage of being readily correlated with present-day views as to the chemical pathogenesis of stones.

4. A series of 100 cases is tabulated and discussed.

The author wishes to express his thanks to Dr. D. W. MacKenzie and Dr. Emerson Smith, successive Heads of the Department of Urology, Royal Victoria Hospital, and to the members of their staff, for the material which has made this paper possible. He also wishes to thank Dr. Leo F. Schiff, Plattsburgh, New York, who furnished the specimens and clinical data described in Case 5. The author is indebted too to the late Dr. William Chase of the Department of Pathology, McGill University, for the material described in Case 4.

\section{BIBLIOGRAPHY}

1. Wollaston, W. H., On cystic oxide, a new species of urinary calculus. Proc. Roy. Soc., London, 1810, $100,223$.

2. Heller, J. F., Die Harnconcretionen, ihre Entstehung, Erkennung, und Analyse mit besonderer Rücksicht auf Diagnose und Therapie der Nieren- und Blasenerkrankung. Wein, Tendler u. Comp., 1860.

3. Domanski, T. J., A classification of urinary calculi, based on composition. Am. J. Clin. Path., Tech. Suppl., 1940, 4, 129.

4. Randall, A., The origin and growth of renal calculi. Ann. Surg., 1937, 105, 1009.

5. Newcomb, C., The rôle of urinary colloids in the prevention of stone formation. Indian J. M. Research, 1930, 18, 275.

6. Hammersten, G., Eine experimentelle Studie über Calciumoxalat als Steinbildner in den Harnwegen. Lunds Universitets Årsskrift, 1935-36, 32.

7. Sisk, I. R., and Toenhart, O., Factors influencing solubility of relatively insoluble salts in urine. $\mathrm{J}$. Urol., 1937, 37, 595.

8. Hammarsten, G., On calcium oxalate and its solubility in the presence of inorganic salts with special reference to the occurrence of oxaluria. Compt. rend. trav. Lab. Carlsberg, 1929, 17, No. 11. The solubility of uric acid and the primary urates in water and salt solutions at 37 deg., with special reference to the formation of sediment in the urinary passages. Ib., 1931, 19, No. 7.

9. Medes, G., Solubility of calcium oxalate and uric acid in solutions of urea. Proc. Soc. Exp. Biol. and Med., 1932, 30, 281. 
10. Hammarsten, G., Dietetic therapy in the formation of calcium oxalate calculi in the urinary passages. Skand. Arch. f. Physiol., 1938, 80, 165.

11. Albright, F., Some medical aspects of the renal stone problem. New England J. Med., 1937, 217, 1063.

12. Hammarsten, G., Harnsauresteine bei Ratten. Skand. Arch. f. Physiol., 1937, 77, 33.

13. Bühler, F., Beitrag zur Frage der Urolithiasis besonders in Verbindung mit Leukaemie und Ruckenmarkverletzungen. Ztschr. f. urol. Chir., 1933, 37, 406.

14. Hammarsten, G., Urinary calculi and their analysis. Nor. Med. (Hygeia), 1940, 7, 1329.

15. Brand, E., Block, R. J., Kassell, B., and Cahill, G. F., Cystinuria V.-The metabolism of casein and lactalbumin. J. Biol. Chem., 1937, 119, 669.

16. Crowell, A. J., Cystin nephrolithiasis; Report of a case with roentgenographic demonstration of disintegration of stone by alkalization. Surg., Gynec. and Obst., 1924, 38, 87.

17. Osborne, T. B., Mendel, L. B., and Ferry, E. L., The incidence of phosphatic urinary calculi in rats fed on experimental rations. J. A. M. A., 1917, 69, 32.

18. McCarrison, $R$., The experimental production of stone in the bladder. Indian J. M. Research, 1926, 14, 895 ; 1927, 15, 197, 485, 801.

19. Higgins, C. C., Experimental production of urinary calculi. J. Urol., 1933, 29, 157.

20. Dixon, W. E., and Hoyle, J. C., Effects of irradiated ergosterol in large doses. Brit. M. J., 1928, 2, 832.

21. Hou, H. C., The influence of diet on the formation of urinary calculi. Chinese M. J., 1936, 50, 787.

22. McCarrison, $R$., The influence of lime in favouring the production of stone in the bladder in rats. Indian J. M. Research, 1930, 17, 1101 ; Further researches on stone. Ibid., 1930, 18, 903.

23. Van der Ryst, M. P. J., Changes in the urinary system and calculus formation in the albino rat, on a diet with a high $\mathrm{CaCO}_{3}$ content. Acta Brevia Neerland., 1936, 6, 45.

24. Ranganathan, S., Researches on "stone." Indian J. M. Research, 1931, 19, 1.

25. Hunter, D., and Turnbull, H. M., Hyperparathyroidism: generalized osteitis fibrosa. Brit. J. Surg., 1931, 19, 203.

26. Albright, F., Baird, P. C., Cope, O., and Bloomberg,
E., Studies of the physiology of the parathyroid glands. Am. J. M. Sc., 1934, 187, 49.

27. Barney, J. D., and Mintz, E. R., The relation of the parathyroid glands to urinary lithiasis. Brit. J. Urol., 1936, 8, 36.

28. Bauer, W., Albright, F., and Aub, J. C., A case of osteitis fibrosa cystica (Osteomalacia?) with evidence of hyperactivity of the parathyroid bodies. J. Clin. Invest., 1930, 8, 229.

29. Albright, F., Aub, J. C., and Bauer, W., Hyperparathyroidism. J. A. M. A., 1934, 102, 1276.

30. Barney, J. D., and Jones, G. E., Some problems in the management of urinary calculi. J. Urol., 1941, 45, 1.

31. Albright, F., Sulkowitch, H. W., and Chute, R., Nonsurgical aspects of the kidney stone problem. J. A. M. A., 1939, 113, 2049.

32. Higgins, C. C., and Schlumberger, F. C., Prevention of the formation of urinary calculi in patients with orthopedic problems. Arch. Surg., 1937, 34, 702.

33. Flocks, R. H., Calcium and phosphorus excretion in the urine of patients with renal or ureteral calculi. J. A. M. A., 1939, 113, 1466. Prophylaxis and medical management of urinary lithiasis: the role of the quantity and precipitability of the urinary calcium. J. Urol., 1940, 44, 183.

34. Hager, B. H., and Magath, T. B., The etiology of encrusted cystitis with alkaline urine. J. A. M. A., 1925, 85, 1352.

35. Chute, R., and Suby, H. I., Prevalence and importance of urea splitting bacterial infections of the urinary tract in the formation of calculi. J. Urol., 1940, 44, 590.

36. Hellström, J., Staphylococcus Stones. A Clinical Study of 90 Cases. Norstedt and Sons, Stockholm, 1936.

37. Burkland, C. E., Etiology and prevention of oxalate calculi in urinary tract: plan of therapy. J. Urol., 1941, 46, 82.

38. Higgins, C. C., Recurrent renal lithiasis. J. Urol., 1938, 40, 184.

39. Fowler, A. F., Personal communication.

40. Domanski, T. J., Analysis of urinary calculi. Am. J. Clin. Path., Tech. Suppl., 1938, 2, 157.

41. Bodansky, M., and Bodansky, O., The Biochemistry of Disease, The MacMillan Co., New York, 1940. 